\title{
Prognostic Potential of MAGEH1 and Its Correlation with Immune infiltrates in Gastric Cancer
}

\author{
Zitong Li \\ Southern Medical University First Affiliated Hospital: Southern Medical University Nanfang Hospital \\ Haoran $\mathrm{Ke}$ \\ Southern Medical University First Affiliated Hospital: Southern Medical University Nanfang Hospital \\ Wenlin Deng \\ Southern Medical University First Affiliated Hospital: Southern Medical University Nanfang Hospital \\ Fang Li \\ Southern Medical University First Affiliated Hospital: Southern Medical University Nanfang Hospital \\ Siqi Wang \\ Southern Medical University First Affiliated Hospital: Southern Medical University Nanfang Hospital \\ Ye Chen ( $\square$ yechen@smu.edu.cn ) \\ Southern Medical University First Affiliated Hospital: Southern Medical University Nanfang Hospital https://orcid.org/0000-0002-7964-7899
}

Primary research

Keywords: MAGEH1, lymphocytes, tumor-infiltrating, prognosis, gastric cancer

Posted Date: March 3rd, 2021

DOI: https://doi.org/10.21203/rs.3.rs-263136/v1

License: (c) (i) This work is licensed under a Creative Commons Attribution 4.0 International License. Read Full License 


\section{Abstract}

Background: MAGEH1 is a critical gene for regulatory T cell function. However, correlations of MAGEH1 to prognosis and tumor-infiltrating cells in different cancers remain unclear. This study was to determine the prognostic impact of MAGEH1 as well as evaluate MAGEH1 expression and immune infiltrate relevance in gastric cancer.

Methods: Oncomine, TIMER2.0, Kaplan-Meier Potter, PrognoScan, Gene Expression Profiling Interactive Analysis (GEPIA), and the Human Protein Atlas database were utilized to analyze the differential MAGEH1 expression and its prognostic value. The relationship between MAGEH1 and gene markers of immune infiltration was confirmed by TIMER2.0 and GEPIA.

Results: The prognostic effect of MAGEH1 varied across cancers. Particularly in gastric cancer, highly expressed MAGEH1 showed a significant association with poor prognosis in multiple databases whereas was linked to a better prognosis in patients with adjuvant 5-fluorouracil therapy. MAGEH1 expression positively correlated with infiltrating levels of B cells, CD8+ T cells, CD4+ T cells, neutrophils, macrophages, and dendritic cells in stomach adenocarcinoma (STAD). Furthermore, MAGEH1 expression showed a strong link with markers for monocytes, macrophages, neutrophils and Tregs in STAD tissues.

Conclusions: MAGEH1 can serve as a prognostic biomarker in gastric cancer and is related to immune infiltrates.

\section{Introduction}

Gastric cancer (GC) is the fifth commonest malignant tumor and the third-greatest cause of tumor mortality in the world [1]. The efficacy of advanced therapies is difficult to improve due to delayed diagnosis and treatment [2-4]. In recent years, the recommendation of immuno-therapy for GC [5, 6] has become a highlight of attention. Several immunotherapies for GC are being tested [7], holding promise for advanced GC. However, in solid tumors, GC is relatively insensitive to immunotherapy. Immunotherapy in GC remains largely unknown [8, 9]. Additionally, the interaction of tumor-infiltrating immune cells and tumor cells would affect the efficacy of GC [10-12]. Therefore, it is important for treating GC to elucidate the interaction mechanism between tumor phenotype and immune-infiltrating cells and to explore novel targets of immunotherapy.

MAGEH1, also known as APR1, is one of the non-cancerous/testicular subgroups of the melanoma-associated antigens superfamily [13]. It is critical for apoptosis, cell cycle inhibition, growth inhibition or cell differentiation [14]. As reported [15], MAGEH1 protein may be a target for atRA signaling via the STAT1-Alpha pathway, which is a crucial element in atRA induction of cell differentiation, and modulate cell growth inhibition and differentiation signals. It is regarded as a cyclin-controlling protein that interacts with P75 in cells [16]. Ojima and his colleagues highlighted the role of negativeexpressed MAGEH1 in the effectiveness of Gemcitabine therapy for biliary cancer [17]. Moreover, previous work stated that low expression of MAGEH1 could promote the progression of hepatocellular carcinoma (LISC) and serve as a marker for prognosis in its patients [18], while over-expressed MAGEH1 predicted an adverse prognosis in breast cancer [19]. These findings suggest that MAGEH1 has an underlying impact on the progression of tumors.

MAGEH1 expression is a unique feature of regulatory T cells (Tregs) in breast cancer, non-small cell lung changer (NSCLC) and colorectal cancer (CRC) $[20,21]$. What's more, high MAGEH1 expression had an association with pessimistic outcomes in NSCLC and CRC patients [21]. The melanomaassociated antigens gene has aroused intense interest in its potential for tumor immunotherapy [22]. However, little information is available on the MAGEH1's function of tumor progression and immune effect in the tumor microenvironment (TME).

Here we explored the MAGEH1's differential expression across various cancers. Furthermore, the prognostic influence of MAGEH1 and its relevance to immune-infiltrating cells was evaluated in multiple public databases. Our data revealed the effect of MAGEH1 on the prognosis of GC and its immunological mechanism and was indicative of a novel treatment strategy for GC.

\section{Results}

\section{The mRNA levels of MAGEH1 in Various Cancers}

Compare to adjacent normal tissues, the elevated MAGEH1 was observed in breast cancer, Leukemia and sarcoma in Oncomine. Whereas the MAGEH1 mRNA level was down-regulated in several cancers (including bladder, brain and CNS, cervical, colorectal, head and neck, liver, lymphoma, melanoma, ovarian and prostate cancers) in some datasets (Figure 1a and Table S1). Other than the Oncomine mentioned above, the datasets from the Cancer Genome Atlas (TCGA) were further applied to verifying the mRNA levels of MAGEH1 by TIMER2.0, which was presented in Figure 1b. Consistent low expression levels of MAGEH1 were seen in tumor samples of BLCA(Bladder Urothelial Carcinoma), BRCA(Breast invasive carcinoma), CESC(Cervical squamous cell carcinoma and endocervical adenocarcinoma), COAD(Colon adenocarcinoma), GBM(Glioblastoma multiforme), KICH(Kidney Chromophobe), KIRC(Kidney renal clear cell carcinoma), KIRP(Kidney renal papillary cell carcinoma), LUAD(Lung adenocarcinoma), LUSC(Lung squamous cell carcinoma), PRAD(Prostate adenocarcinoma), READ(Rectum adenocarcinoma), STAD(Stomach adenocarcinoma), THCA(Thyroid carcinoma) and UCEC( Uterine Corpus Endometrial Carcinoma), than normal tissue based on both comparisons. Meanwhile, MAGEH1 expression noticeably increased by $\mathrm{CHOL}$ (Cholangiocarcinoma) and HNSC (Head and Neck squamous cell carcinoma) (Figure 1b). 


\section{MAGEH1 Expression-prognosis Association}

We next investigated MAGEH1 and oncologic outcome relevance in order to verify its clinical significance. Figure S3 provided an overview of the MAGEH1 expression-prognosis association in PrognoScan. Prognosis of 8 cancers dramatically associated with MAGEH1 in PrognoScan was screened with Cox-P $<0.05$ as a threshold, which including bladder cancer, acute myeloid leukemia, Glioma, breast cancer, CRC, eye cancer, LUAD, and liposarcoma (Figure S3). Multiple cohorts of CRC (GSE17536, GSE14333, GSE17537) and breast cancer (GSE12276, GSE1378, GSE1379, GSE9893, GSE2034) showed that MAGEH1 was a markedly favorable prognostic marker. Results infer that MAGEH1 highly expressed was an independent risk factor for the adverse outcome of CRC and breast cancer patients.

Except for the above micro array analysis from PrognoScan which was mainly extracted from the Gene Expression Synthesis database, the KaplanMeier plotter database also demonstrated the survival potential of MAGEH1 mRNA in various cancers based on gene chip. As shown in Fig. 2, the elevated MAGEH1 expression correlated with worsen prognosis in GC (Hazard ratio(HR): 1.29, 95\% confidence intervals $(\mathrm{Cl})$ : $1.08-1.53, \mathrm{P}=0.0037$; HR: $1.43,95 \% \mathrm{Cl}: 1.14-1.78, \mathrm{P}=0.0016$, overall survival (OS) and post-progression survival (PPS), respectively) (Fig. 2a,b), and was prognostic for OS (HR: 0.56, 95\% Cl: 0.49-0.63, P囚1e-16) and PPS (HR: 0.65, 95\% Cl: 0.5-0.84, P=0.00076)in lung cancer (Fig. 2c,d). MAGEH1 expression had less influence on ovarian cancer and as reported [19], high MAGEH1 expression had an association with inferior RFS in breast cancer (Fig. 2h).

The prognostic value of MAGEH1 in diverse neoplasms was further validated by Gene Expression Profiling Interactive Analysis (GEPIA) (Figure S1) and Human Protein Atlas database (HPA) analysis, which based on RNA-seq datasets from TCGA. Highly expressed MAGEH1 was beneficial to prognosis for OS and disease-free survival (DFS) in LGG (Brain Lower Grade Glioma), OV (ovarian serous cystadenocarcinoma) and PAAD (Pancreatic adenocarcinoma) (Figure S1.ac-ad, am-an, ao-ap), OS in LUAD and DFS in SKCM (Skin Cutaneous Melanoma) and THCA (Figure S1ag, az, bf); and had a negative prognostic impact on OS and DFS in STAD as well as OS in LIHC (Figure S1ba-bb, ae). Meanwhile, lowly-expressed MAGEH1 significantly related to increased survival in UCEC and STAD and decreased survival in LGG, LUAD and OV, PAAD, KIRC, (Figure2i-o) in HPA (based on p『0.01). The combination of multiple databases confirms the prognostic effect of MAGEH1 in some tumors, especially in GC.

\section{The Discrepancy Expression of MAGEH1 in a layered STAD Population}

We validated the relationship between MAGEH1 and clinicopathological factors in GC in Kaplan-Meier Plotter for exploring its relevance and potential mechanisms. As shown in Fig. 3, MAGEH1 had statistically inverse correlation with OS in male ( $\mathrm{N}=544, \mathrm{HR}: 1.3,95 \% \mathrm{Cl}$ : 1.05-1.61), stage 3-4(N= 305, HR: $1.4,95 \%$ Cl: $1.05-1.87 ; \mathrm{N}=148$, HR: 1.49, 95\% Cl: 1.01-2.2), and stage T ( $\mathrm{N}=38, \mathrm{HR}: 2.57,95 \%$ Cl:1.02-6.49) of patients. Meanwhile, Patients with highly expressed MAGEH1 in the following characteristics, Stage N1 ( $\mathrm{N}=225, \mathrm{HR}: 2.1,95 \% \mathrm{Cl}: 1.37-3.2 ; \mathrm{N}=222, \mathrm{HR}$ : 1.64, 95\% Cl: 1.11-2.44, OS and PFS respectively), and Stage M0 ( $\mathrm{N}=444, \mathrm{HR}: 1.6,95 \% \mathrm{Cl}: 1.21-2.12 ; \mathrm{N}=443, \mathrm{HR}: 1.38,95 \% \mathrm{Cl}: 1.06-1.81,0 \mathrm{~S}$ and PFS respectively), and in intestinal ( $=320$, HR: 1.68, 95\% Cl: 1.22-2.32; N = 263, HR: 1.67, 95\% Cl: 1.17-2.39, OS and PFS respectively) and Diffuse (N=241, HR: 1.86, 95\% Cl: 1.31-2.63; $\mathrm{N}=231$, HR: $1.63,95 \% \mathrm{Cl}$ : 1.15-2.31, OS and PFS respectively) types classified by Lauren had poorer OS and PFS; The association was statistically significant. These results are suggestive of the prognostic effect of MAGEH1 on GC in specific groups (Fig. 3).

Notably, as can be seen from Figure3, the elevated MAGEH1 had a markedly improved OS ( $\mathrm{N}=152, \mathrm{HR}: 0.62,95 \% \mathrm{Cl}: 0.43-0.88)$ in GC patient receiving adjuvant 5- fluorouracil (5-FU); This was the opposite of patients who surgery alone ( $\mathrm{N}=380, \mathrm{HR}: 1.37,95 \% \mathrm{Cl}$ : 1.03-1.83). This observation may have clinical significance for GC patients with high MAGEH1 levels, as MAGEH1-high status may be utilized to identify patients who would benefit from adjuvant 5-FU-based therapy.

\section{The discrepancy between ACC, STAD and LGG in Associations of MAGEH1 Expression and Immune Infiltration}

According to the importance of tumor-infiltrating lymphocytes $[23,24]$ and MAGEH1 in neoplasm prognosis, we explored whether MAGEH1 would be conducive to recruiting more immune cells into TME, thus afflicting the oncologic outcome. We carried out TIMER2.0 to assess the relationship between MAGEH1 and immunoinfiltration in 39 neoplasms. The results displayed MAGEH1 expression remarkably linked to tumor purity of 16 types of cancer. Moreover, the levels of infiltration of B cells, CD8 + T cells, CD4 + T cells, dendritic cells (DCs), macrophages, and neutrophils (19, 19, 11, 24, 29, and 28 cancer types, respectively) had an association with MAGEH1 expression through TIMER algorithms (Figure S2).

The data of TIMER2.0, GEPIA and HPA are all mainly from TCGA database. Therefore, based on the above prognostic consequences in GEPIA and HPA, we finally selected LGG and ACC (Adrenocortical carcinoma) with different associations between prognosis and MAGEH1 expression than STAD as the control for comparison. Interestingly, we found that the relevance between increased expression of MAGEH1 and immune infiltration after adjusting for tumor purity was dramatically distinct in STAD and LGG. A positive correlation was found betweenMAGEH1 expression and the levels of infiltration of B cells, CD8+ T cells, CD4+ T cells, macrophages, neutrophils as well as DCs ( $r=0.108,0.338,0.391,0.582,0.282$, and 0.365 , respectively) in STAD (Figure 4a). Furthermore, negative associations with the infiltration of macrophages, neutrophils, and DCs ( $r=0.133,0.298$, and 0.461 , respectively) and positive relations with CD8+ T cells and CD4+ T cells ( $r=0.229$ and 0.389 , respectively) were observed in LGG (Figure 4c). Meanwhile, MAGEH1 was not statistically correlated to tumor purity and the above 6 cells in ACC. These findings illustrate the association with immune infiltration in STAD, while differing from LGG where the prognosis was positively correlated with MAGEH1. 
Therefore, we next investigated the relationship between MAGEH1 and immunomarker genes, which characterized immune cells among STAD, ACC and LGG. We found that after adjustment for tumor purity, not statistically significant correlations existed in ACC. However, in STAD and LGG, MAGEH1 expression was markedly related to most markers of multiple innate and acquired immune cells (Table 1). As expected, most immune markers had positive coefficients in STAD negatively correlated in LGG, but the two focused on different types of immune cells. Hence, it could conceivably be hypothesized that the expression profile of MAGEH1 in STAD and LGG was associated with separate infiltrating patterns of TME, which can explain the noticeable variations in the associations across MAGEH1 and patient survival in the two types of cancers. Specifically, A strong link with MAGEH1 expression was observed in genetic markers of macrophages (monocytes, tumor-related macrophages (TAMs) and M2 macrophages), neutrophils and Treg cells than others in STAD (Table 1), while LGG was mainly associated with antigen-presenting DCs. 
Table 1

Correlation analysis between MAGEH1 and gene markers of immune cells in TIMER2.0.

\begin{tabular}{|c|c|c|c|c|c|c|c|c|c|c|c|c|c|}
\hline \multirow[t]{3}{*}{ Description } & \multirow{3}{*}{$\begin{array}{l}\text { Genemarkers } \\
\text { infiltrates }\end{array}$} & \multicolumn{4}{|l|}{ STAD } & \multicolumn{4}{|l|}{ ACC } & \multicolumn{4}{|l|}{ LGG } \\
\hline & & \multicolumn{2}{|l|}{ None } & \multicolumn{2}{|l|}{ Putiry } & \multicolumn{2}{|l|}{ None } & \multicolumn{2}{|l|}{ Putiry } & \multicolumn{2}{|l|}{ None } & \multicolumn{2}{|l|}{ Putiry } \\
\hline & & Cor & $\mathrm{p}$ & Cor & $\mathrm{p}$ & Cor & $\mathrm{p}$ & Cor & $\mathrm{p}$ & Cor & $\mathrm{p}$ & Cor & $\mathrm{p}$ \\
\hline \multirow[t]{4}{*}{ Neutrophils } & CD66b(CEACAM8) & -0.054 & 0.272 & -0.031 & 0.544 & -0.043 & 0.705 & -0.027 & 0.822 & -0.063 & 0.150 & -0.060 & 0.192 \\
\hline & CD11b(ITGAM) & 0.430 & $\star \star \star$ & 0.426 & $\star \star \star ~$ & 0.001 & 0.991 & 0.068 & 0.568 & -0.442 & $\star \star \star$ & -0.340 & $\star \star \star$ \\
\hline & CCR7 & 0.438 & $\star \star \star$ & 0.423 & $\star \star \star \star ~$ & 0.172 & 0.130 & 0.240 & 0.041 & -0.097 & 0.027 & -0.054 & 0.242 \\
\hline & CD54(ICAM-1) & 0.191 & $\star \star \star$ & 0.172 & ** & -0.049 & 0.671 & -0.061 & 0.610 & -0.469 & 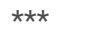 & -0.437 & $\star \star \star$ \\
\hline \multirow{7}{*}{$\begin{array}{l}\text { Natural killer } \\
\text { cell }\end{array}$} & KIR2DL1 & 0.119 & 0.015 & 0.121 & 0.018 & 0.017 & 0.885 & 0.073 & 0.538 & 0.032 & 0.466 & 0.003 & 0.954 \\
\hline & KIR2DL3 & -0.025 & 0.607 & -0.059 & 0.250 & -0.071 & 0.534 & -0.028 & 0.815 & -0.124 & * & -0.113 & 0.014 \\
\hline & KIR2DL4 & -0.124 & 0.011 & -0.155 & * & 0.004 & 0.969 & 0.065 & 0.586 & -0.257 & $\star \star \star$ & -0.258 & $\star \star \star *$ \\
\hline & KIR2DS4 & 0.057 & 0.249 & 0.036 & 0.486 & -0.078 & 0.495 & -0.014 & 0.906 & -0.026 & 0.549 & 0.013 & 0.773 \\
\hline & KIR3DL1 & 0.145 & * & 0.133 & * & -0.034 & 0.769 & -0.018 & 0.880 & -0.013 & 0.769 & -0.008 & 0.863 \\
\hline & KIR3DL2 & 0.135 & * & 0.129 & 0.012 & -0.014 & 0.902 & 0.013 & 0.912 & -0.157 & $\star \star$ & -0.164 & $\star \star$ \\
\hline & KIR3DL3 & -0.144 & * & -0.134 & * & -0.092 & 0.421 & -0.077 & 0.516 & -0.061 & 0.165 & -0.050 & 0.276 \\
\hline \multirow{7}{*}{$\begin{array}{l}\text { Dendritic } \\
\text { cell }\end{array}$} & HLA-DPA1 & 0.243 & $\star \star \star *$ & 0.221 & $\star \star * *$ & -0.099 & 0.385 & -0.064 & 0.589 & -0.428 & $\star * \star$ & -0.369 & $\star \star \star *$ \\
\hline & HLA-DPB1 & 0.303 & 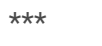 & 0.280 & $\star \star \star ~$ & -0.070 & 0.539 & -0.029 & 0.810 & -0.468 & $\star \star \star *$ & -0.412 & $\star * \star$ \\
\hline & HLA-DQB1 & 0.160 & * & 0.131 & 0.011 & -0.174 & 0.126 & -0.160 & 0.175 & -0.390 & $\star \star \star ~$ & -0.343 & $\star \star \star$ \\
\hline & HLA-DRA & 0.201 & $\star \star \star \star$ & 0.178 & ** & -0.076 & 0.508 & -0.032 & 0.788 & -0.465 & $\star \star \star *$ & -0.407 & $\star \star \star *$ \\
\hline & CD1C(BDCA-1) & 0.509 & $\star \star \star \star ~$ & 0.504 & $\star \star \star$ & 0.070 & 0.543 & 0.157 & 0.184 & -0.159 & $\star \star$ & -0.118 & * \\
\hline & NRP1 & 0.551 & $\star \star \star *$ & 0.542 & $\star \star \star *$ & 0.145 & 0.201 & 0.095 & 0.426 & -0.017 & 0.706 & -0.043 & 0.343 \\
\hline & ITGAX(CD11c) & 0.329 & 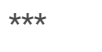 & 0.310 & $\star \star \star *$ & 0.050 & 0.661 & 0.102 & 0.393 & -0.435 & $\star \star \star *$ & -0.343 & $\star \star \star *$ \\
\hline \multirow[t]{2}{*}{ Monocyte } & CD86 & 0.376 & $\star \star \star *$ & 0.360 & $* * *$ & -0.170 & 0.134 & -0.135 & 0.257 & -0.427 & $\star \star *$ & -0.336 & $\star * *$ \\
\hline & CD115(CSF1R) & 0.504 & $\star \star \star$ & 0.490 & $\star \star \star \star$ & -0.096 & 0.398 & -0.054 & 0.648 & -0.365 & $\star \star \star \star$ & -0.252 & $\star \star \star \star ~$ \\
\hline \multirow{4}{*}{$\begin{array}{l}\text { M1 } \\
\text { Macrophage }\end{array}$} & INOS(NOS2) & -0.119 & 0.015 & -0.133 & * & 0.187 & 0.099 & 0.204 & 0.084 & 0.013 & 0.777 & 0.034 & 0.457 \\
\hline & IRF5 & 0.271 & $\star \star \star *$ & 0.267 & 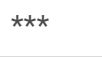 & 0.051 & 0.656 & 0.103 & 0.384 & -0.464 & $\star \star \star *$ & -0.383 & $\star \star \star *$ \\
\hline & COX2(PTGS2) & 0.195 & $\star \star \star *$ & 0.198 & ** & 0.091 & 0.425 & 0.099 & 0.403 & -0.155 & ** & -0.101 & 0.028 \\
\hline & IRF8 & 0.020 & 0.680 & 0.015 & 0.774 & 0.074 & 0.519 & 0.158 & 0.181 & -0.273 & $\star \star \star ~$ & -0.164 & $\star \star$ \\
\hline \multirow{4}{*}{$\begin{array}{l}\text { M2 } \\
\text { Macrophage }\end{array}$} & CD163 & 0.361 & $\star \star \star \star ~$ & 0.344 & $\star \star \star *$ & 0.061 & 0.593 & 0.105 & 0.375 & -0.331 & $\star \star \star *$ & -0.320 & $\star \star \star \star$ \\
\hline & MS4A4A & 0.446 & $\star \star \star *$ & 0.439 & $\star \star *$ & -0.021 & 0.852 & 0.040 & 0.736 & -0.316 & $\star * *$ & -0.289 & $\star * *$ \\
\hline & MRC1(CD206) & 0.391 & $\star * \star$ & 0.378 & $\star \star *$ & -0.020 & 0.862 & 0.039 & 0.743 & 0.064 & 0.144 & 0.129 & * \\
\hline & VSIG4 & 0.400 & $\star \star \star \star ~$ & 0.402 & $\star \star \star *$ & -0.048 & 0.674 & -0.009 & 0.942 & -0.335 & $\star \star \star$ & -0.255 & $\star \star \star *$ \\
\hline \multirow[t]{3}{*}{ TAM } & CCL2 & 0.534 & $\star \star \star \star ~$ & 0.527 & $\star \star \star *$ & 0.103 & 0.365 & 0.180 & 0.127 & -0.405 & $\star * *$ & -0.362 & $\star \star \star *$ \\
\hline & CD68 & 0.180 & ** & 0.157 & * & 0.110 & 0.333 & 0.219 & 0.063 & -0.410 & $\star \star \star$ & -0.339 & $\star \star \star$ \\
\hline & IL10 & 0.394 & $\star \star \star *$ & 0.386 & $\star \star \star ~$ & -0.056 & 0.626 & -0.018 & 0.881 & -0.355 & $\star \star \star *$ & -0.291 & $\star \star \star *$ \\
\hline \multirow{3}{*}{$\begin{array}{l}\text { T cell } \\
\text { (general) }\end{array}$} & CD3D & 0.284 & $\star \star \star$ & 0.262 & CD3 & 0.071 & 0.534 & 0.133 & 0.263 & -0.339 & $\star \star \star ~$ & -0.275 & 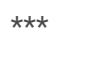 \\
\hline & CD3E & 0.297 & $\star \star \star \star ~$ & 0.281 & $\star \star \star *$ & -0.026 & 0.818 & 0.052 & 0.659 & -0.350 & $\star \star \star *$ & -0.304 & $\star * *$ \\
\hline & CD2 & 0.318 & $\star \star \star *$ & 0.302 & $\star \star \star *$ & 0.022 & 0.850 & 0.137 & 0.249 & -0.355 & $\star \star \star *$ & -0.311 & $\star * \star$ \\
\hline \multirow[t]{2}{*}{ B cell } & CD19 & 0.401 & $\star \star \star \star ~$ & 0.389 & $\star \star \star *$ & 0.204 & 0.071 & 0.204 & 0.084 & -0.308 & $\star \star \star *$ & -0.239 & $\star \star \star *$ \\
\hline & CD79A & 0.411 & $\star \star \star *$ & 0.388 & $\star \star \star *$ & -0.125 & 0.273 & -0.115 & 0.333 & -0.214 & $\star \star \star *$ & -0.223 & $\star \star \star *$ \\
\hline CD8+Tcell & CD8A & 0.259 & $\star * *$ & 0.237 & $\star \star \star *$ & 0.102 & 0.370 & 0.176 & 0.137 & -0.220 & $\star \star \star *$ & -0.112 & 0.014 \\
\hline
\end{tabular}




\begin{tabular}{|c|c|c|c|c|c|c|c|c|c|c|c|c|c|}
\hline & CD8B & 0.263 & $\star \star \star *$ & 0.263 & $\star \star \star ~$ & 0.023 & 0.837 & 0.087 & 0.465 & -0.191 & 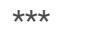 & -0.088 & 0.054 \\
\hline \multirow[t]{2}{*}{ Tfh } & BCL6 & 0.457 & $\star * *$ & 0.447 & $\star \star \star$ & 0.152 & 0.181 & 0.127 & 0.284 & 0.001 & 0.977 & -0.033 & 0.467 \\
\hline & IL21 & 0.115 & 0.019 & 0.115 & 0.026 & NA & NA & NA & NA & -0.103 & 0.019 & -0.098 & 0.032 \\
\hline \multirow[t]{5}{*}{ Treg } & FOXP3 & 0.298 & $\star \star \star *$ & 0.268 & $\star \star \star$ & 0.111 & 0.329 & 0.088 & 0.461 & 0.214 & $\star \star \star$ & 0.214 & $\star \star \star$ \\
\hline & CCR8 & 0.319 & $\star \star \star$ & 0.305 & $\star \star \star$ & 0.113 & 0.320 & 0.156 & 0.189 & -0.136 & * & -0.135 & * \\
\hline & STAT5B & 0.470 & $\star * *$ & 0.457 & $\star \star \star *$ & 0.355 & * & 0.366 & * & 0.225 & $\star * \star$ & 0.159 & ** \\
\hline & TNF $\beta$ (TGFB1) & 0.534 & $\star \star \star$ & 0.514 & $\star \star \star$ & -0.037 & 0.744 & -0.012 & 0.918 & -0.502 & $\star \star \star$ & -0.456 & $\star \star \star$ \\
\hline & CD25(IL2) & 0.131 & * & 0.136 & * & 0.197 & 0.082 & 0.219 & 0.063 & -0.165 & $\star *$ & -0.176 & ** \\
\hline \multirow[t]{5}{*}{ Th1 } & T-bet(TBX21) & 0.233 & $\star \star \star *$ & 0.216 & $\star \star \star *$ & -0.037 & 0.744 & 0.015 & 0.903 & -0.166 & $\star *$ & -0.164 & $\star \star$ \\
\hline & STAT4 & 0.388 & $\star \star \star$ & 0.377 & $\star \star \star \star$ & -0.004 & 0.970 & 0.045 & 0.703 & 0.023 & 0.599 & 0.099 & 0.031 \\
\hline & STAT1 & -0.023 & 0.635 & -0.034 & 0.510 & 0.247 & 0.028 & 0.227 & 0.054 & -0.124 & * & -0.102 & 0.026 \\
\hline & IFN-y(IFNG) & -0.060 & 0.225 & -0.072 & 0.163 & 0.166 & 0.145 & 0.216 & 0.067 & -0.215 & $\star \star \star *$ & -0.172 & $\star \star$ \\
\hline & TNF-a(TNF) & 0.149 & * & 0.118 & 0.021 & 0.097 & 0.396 & 0.190 & 0.107 & -0.114 & * & -0.053 & 0.247 \\
\hline \multirow[t]{4}{*}{ Th2 } & GATA3 & 0.364 & $\star \star \star \star$ & 0.364 & $\star \star \star \star$ & 0.083 & 0.468 & 0.030 & 0.800 & -0.402 & $\star \star \star \star$ & -0.372 & $\star \star \star$ \\
\hline & STAT5A & 0.284 & 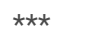 & 0.289 & $\star \star \star$ & 0.370 & ** & 0.407 & ** & -0.518 & $\star \star \star$ & -0.435 & $\star \star \star$ \\
\hline & STAT6 & 0.149 & * & 0.152 & * & 0.426 & $\star \star \star *$ & 0.430 & ** & -0.407 & $\star \star \star *$ & -0.288 & $\star \star \star *$ \\
\hline & IL13 & 0.087 & 0.076 & 0.107 & 0.037 & 0.128 & 0.261 & 0.101 & 0.395 & -0.051 & 0.246 & -0.075 & 0.103 \\
\hline \multirow[t]{2}{*}{ Th17 } & STAT3 & 0.292 & $\star \star \star *$ & 0.284 & $\star \star \star$ & 0.375 & ** & 0.354 & * & -0.179 & $\star \star \star$ & -0.172 & ** \\
\hline & IL17A & -0.069 & 0.159 & -0.084 & 0.101 & 0.000 & 0.997 & 0.018 & 0.881 & 0.038 & 0.391 & 0.049 & 0.288 \\
\hline \multirow{5}{*}{$\begin{array}{l}\text { T cell } \\
\text { exhaustion }\end{array}$} & PD-1(PDCD1) & 0.199 & $\star \star \star *$ & 0.184 & ** & -0.087 & 0.447 & -0.033 & 0.784 & -0.353 & $\star \star \star$ & -0.334 & $\star \star \star$ \\
\hline & CTLA4 & 0.154 & * & 0.130 & 0.012 & -0.024 & 0.837 & 0.032 & 0.789 & -0.295 & $\star \star \star *$ & -0.240 & $\star \star \star$ \\
\hline & GZMB & -0.010 & 0.841 & -0.057 & 0.266 & -0.203 & 0.072 & -0.170 & 0.151 & -0.137 & * & -0.137 & * \\
\hline & TIM-3(HAVCR2) & 0.324 & $\star \star \star *$ & 0.315 & $\star \star \star *$ & 0.157 & 0.168 & 0.249 & 0.034 & -0.445 & $\star * \star$ & -0.356 & $\star \star \star *$ \\
\hline & LAG3 & 0.115 & 0.019 & 0.096 & 0.062 & -0.077 & 0.501 & -0.093 & 0.434 & -0.127 & * & -0.165 & $\star *$ \\
\hline
\end{tabular}

Subsequently, we performed the GEPIA database to investigate the relevance of MAGEH1 expression and the above immune cell markers in STAD, revealing similar correlations with those of the TIMER analysis (Table 2). After adjusting tumor purity, markers of monocyte (CD86, CSF1R), TAM (CCL2, IL10), M2 macrophage (CD163, VSIG4, MS4A4A, MRC1, VSIG4), neutrophils (CD11b, CCR7), and Treg (CCR8, FOXP3, STAT5B, TGFbeta1) had strong relation to MAGEH1 in STAD ( $<<0.0001$; Table 1), which was also corroborated by GEPIA later (Table 2). Together, these results reveal that MAGEH1 may be crucial in immunologic escape and immune tolerance in TME in STAD. 
Table 2

Correlations between MAGEH1 and genes markers of monocytes, macrophages, neutrophils and Tregs in STAD in GEPIA.

\begin{tabular}{|c|c|c|c|c|c|}
\hline Description & Gene markers & tumor & & normal & \\
\hline & infiltrates & $\mathbf{R}$ & $\mathbf{p}$ & $\mathbf{R}$ & $p$ \\
\hline \multirow[t]{2}{*}{ Monocyte } & CD86 & 0.36 & $\star \star \star$ & 0.13 & 0.45 \\
\hline & CD115 (CSF1R) & 0.48 & $\star * \star$ & 0.4 & 0.016 \\
\hline \multirow[t]{3}{*}{ TAM } & CCL2 & 0.53 & $\star \star \star$ & 0.57 & ** \\
\hline & CD68 & 0.17 & ** & -0.49 & * \\
\hline & IL10 & 0.38 & $\star \star \star$ & 0.32 & 0.056 \\
\hline M1 & INOS (NOS2) & -0.13 & 0.011 & 0.13 & 0.46 \\
\hline \multirow[t]{3}{*}{ Macrophage } & IRF5 & 0.25 & $\star \star \star \star ~$ & -0.55 & ** \\
\hline & COX2(PTGS2) & 0.23 & $\star \star \star \star ~$ & 0.68 & $\star \star \star$ \\
\hline & IRF8 & 0.028 & 0.57 & -0.004 & 0.98 \\
\hline M2 & CD163 & 0.35 & 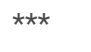 & 0.77 & 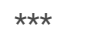 \\
\hline \multirow[t]{3}{*}{ Macrophage } & MS4A4A & 0.42 & $\star \star \star *$ & 0.84 & $\star \star \star \star ~$ \\
\hline & MRC1(CD206) & 0.87 & 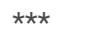 & 0.82 & $\star \star \star$ \\
\hline & VSIG4 & 0.38 & $\star * \star$ & 0.74 & $\star \star \star \star ~$ \\
\hline \multirow[t]{4}{*}{ Neutrophils } & CD66b(CEACAM8) & -0.045 & 0.36 & 0.24 & 0.16 \\
\hline & CD11b(ITGAM) & 0.4 & $\star \star *$ & 0.67 & $\star \star \star *$ \\
\hline & CCR7 & 0.42 & $\star \star \star \star ~$ & -0.28 & 0.096 \\
\hline & CD54(ICAM-1) & 0.18 & ** & 0.33 & 0.051 \\
\hline \multirow[t]{5}{*}{ Treg } & FOXP3 & 0.27 & $\star \star \star \star ~$ & -0.37 & 0.026 \\
\hline & CCR8 & 0.31 & $\star * *$ & -0.39 & 0.019 \\
\hline & STAT5B & 0.45 & $\star \star \star$ & 0.7 & $\star \star \star$ \\
\hline & TNF $\beta$ (TGFB1) & 0.51 & $\star \star \star \star ~$ & 0.11 & 0.52 \\
\hline & CD25(IL2) & -0.091 & 0.067 & -0.27 & 0.11 \\
\hline
\end{tabular}

TAM, tumor-associated macrophage; Treg, regulatory T cell; Tumor, correlation analysis in tumor tissue of stomach adenocarcinoma in TCGA; Normal, correlation analysis in normal tissue of stomach adenocarcinoma in TCGA. ${ }^{*} \mathrm{P}<0.01 ; * \star \mathrm{P}<0.001 ;{ }^{* \star *} \mathrm{P}<0.0001$.

\section{Discussion}

Although MAGEH1 is rarely examined, it is known to be upregulated in activated Treg and CD8 $+\mathrm{T}$ cells. Recent investigates have stressed the importance of MAGEH1 in tumorigenesis and cancer development [17-19, 21, 25]. In this study, variations in MAGEH1 expression levels appeared to associate with prognosis in different cancer types. MAGEH1 highly expressed correlated with a favorable prognosis in LUAD and PRAD and worsened the prognosis in STAD and BRCA. Unexpectedly, the increased expression of MAGEH1 was beneficial to the outcome of GC patients with adjuvant therapy, pointing out the MAGEH1's prediction for tumor efficacy. Furthermore, we found that STAD and LGG have different patterns for relevance between immune infiltration and MAGEH1. Therefore, this work provides insights into MAGEH1 as a biomarker for prognosis and therapeutic effect of GC from the tumor immunology viewpoint, which contributes to future mechanism research and the development of immunotherapy.

Here we profiled the difference of MAGEH1 expression and the visualization of prognostic landscape in various tumors utilizing data from Oncomine, PrognoScan and TCGA. Compare to normal tissues, the mRNA levels of MAGEH1 varied among different tumors, and most of them were downregulated. For example, decreased expression of MAGREH1 in liver cancer tissues corroborates the previous finding [18] (Fig. 1a and Table S1.). This might be due to certain factors leading to gene silencing, such as transformation-dependent DNA hypermethylation, which is common in cancer cells [26]. However, further investigates are needed to determine the specific relationship between MAGEH1 and methylation. In multiple databases, high MAGEH1 expression dramatically linked to better survival of LUAD and PAAD, and worse prognosis of STAD and BRCA, even though there are remarkable variations among different databases due to diversities in sample collection methods, processing standards, as well as samples themselves (Fig. 2, Table S1, Figure S1,3). Unlike De Simone [21], who argued highly expressed MAGEH1 predicted a poor 5-year survival of NSCLC patients after adjusting for T cell density, we found LUAD patients with elevated MAGEH1 was remarked related to positive prognosis (Fig. 2 and Figure S1). The different range of tumor types included may account for this contradiction, such as MAGEH1 had a correlation with LUAD prognosis in lung 
cancer, rather than LUSC (Figure S1). Moreover, various clinical trial endpoints (Figure S1), as well as treatment methods in the study population may lead to diversity in results. Therefore, further research is required, including more patients and more detailed and improved designs. In addition, MAGEH1 was an adverse prognostic factor for GC in stage N1, M0, intestinal and diffuse by Lauren classification, as well as surgery only (Fig. 3). Taken together, MAGEH1 may be a promising prognostic marker for gastric, lung, breast, and prostate cancers.

Interestingly, in the treatment of GC, the elevated expression of MAGEH1 in patients with adjuvant 5-FU was substantially correlated with a favorable prognosis, which differed from whose surgery alone. We speculate MAGEH1 can reverse 5-FU resistance of GC. Over-expression of MAGEH1 has been reported to overcome melanoma resistance to current therapies by interacting with the juxtamembrane region of p75 neurotrophic receptor [29]. Disordered apoptosis is linked to cancer treatment resistance [27]. While 5-FU interferes with DNA replication by inhibiting thymidylate synthase, and consequently, apoptosis and cell cycle arrest [28], and its effect is limited by the drug resistance of GC. Therefore, it is reasonable to consider that the anti-apoptotic effect of MAGEH1 can partly overcome the tumor resistance to 5-FU and thus improve the prognosis of patients. Up to now, there is little published data on the relationship between MAGEH1 and GC. Additional research is needed to validate this hypothesis, which may help to better define patients who are clinically appropriate to receive adjuvant chemotherapy. This result points to MAGEH1 as a predictive factor responding to postsurgical chemotherapy, rather than being only a prognostic indicator.

Another finding was the association of MAGEH1 expression with varying degrees of immune infiltrates in TME, especially in STAD. TME contains tumor cells and other cells, with tumor-infiltrating lymphocytes accounts for a large proportion. Accumulation of TAMs and Tregs in the TME is a major element in immune evasion and immunosuppression, thus promoting tumor growth and invasion. Moreover, a variety of immunoinfiltrating cells contained in the TME, also participate in cancer development [30]. MAGEH1 expression was negatively correlated to tumor purity in STAD, contrary to the correlation in LGG, which denotes it is relatively enriched in tumor cells in STAD. Therefore, the assessment regarding the MAGEH1-immune infiltration relationship adjusted the purity of the tumor to obviate the confounding effects by tumor purity [31]. We found that MAGEH1 expression optimistically associated with the 6 immune infiltrating cells in STAD, while most negatively correlated in LGG, as expected. This also reflects the heterogeneity of tumors and various roles of MAGEH1 in different tumors.

Meanwhile, the MAGEH1 and immune-related markers relevance also demonstrate MAGEH1 in the regulation of tumor immunity in STAD. Our results revealed a strong link between MAGEH1 and neutrophils. We know that neutrophils regulate many malignance-related behaviors of cancer cells, such as migration and invasion, and may accelerate GC progression by inhibiting T cell function [32]. Under certain assumptions, we can be construed that MAGEH1 may partially inhibit T cell function in the regulation of neutrophils, but not in the way of PD-1 dependence. Interestingly, MAGEH1 was positively correlated with immune markers regarding TAM, monocytes, macrophages, and Treg cells. Although we cannot account for this phenomenon by describing a cell-specific mechanism, clues may be found from ex-pressed markers concerning TAM. The most critical pathways for TAM recruitment and proliferation are the CSF-1 /CSR-1 signal and the CCL2/CCR2 axis [33], which are crucial for macrophage survival and M1 to M2 transformation. What's more, some drugs inhibiting TAM recruitment have achieved definite clinical efficacy [33]. The strong correlation between CSF-1, CCL2, M2, and TAM-related immune markers and MAGEH1 reveals the potential regulatory effect of MAGEH1 on the recruitment of monocytes/macrophages, Tregs and M2 polarization. Tumor-infiltrating Tregs can inhibit anti-cancer immunity, thus hindering immunosurveillance and hampering effective antitumor immune responses, sequentially accelerating tumor progression in a broad range of cancer types including GC [34]. FOXP3 and TGF- $\beta$ are essential for Tregs to regulate effector T cells' function $[35,36]$. Based on the strong correlation between FOXP3, TGF- $\beta$ and MAGEH1, presumably, MAGEH1 is a potential marker for the tumor immunization of Tregs, influencing the immune response of effector $T$ cells, thereby promoting tumor development. Although the results showed that there was positive relevance between MAGEH1 and CD8 + T cell (Fig. 4, Table 1, 2), MAGEH1 may play a negative role in interfering with CD $8+T$ cell functions by forming a complex dynamic coordination network with various tumorinfiltrating immune cells (Tregs, TAMs, neutrophils) within TME thus facilitating tumor immune escape. The analysis of the relationship between MAGEH1 and tumor immunogenicity represents a new aspect of MAGEH1 research and highlights the importance of studying the immunotherapeutic effect of MAGEH1 in different tumor types in the future.

Recent work about MAGEH1 may provide some explanations for the potential mechanisms. MAGEH1 may act as E3 ubiquitin ligase, which affects the function or survival of Treg in cancer tissues and accelerates tumor growth and metastasis [37, 38]. Increased expression of MAGEH1 has been reported in numerous tumors' Treg cells, such as breast cancer, CRC, and malignant cell lung cancer [21, 37]. Indeed, Tregs have been emphasized in accelerating tumorigenesis and progression by specifically inhibiting tumor-reactive T cells [34]. Besides, altered subcellular localization of MAGEH1 may affect its function. MAGEH1 is mainly localized to the nucleus in normal cells but is predominantly detected in the cytoplasm of tumor cells [39]. The subcellular localization of proteins is vital for their physiological function [40]. MAGEH1 may transfer from nucleus to cytoplasm, afterwards the different domains and subcellular location of MAGEH1 affect its subcellular functions, such as regulating cell cycle and promoting apoptosis [15, 16, $25,29]$.

However, despite the integration of information from multiple databases to analyze the expression and the impact of MAGEH1 on the oncologic outcome, the mechanisms of MAGEH1 have not been fully elucidated in cell and animal studies. Moreover, potential epigenetic mechanisms of MAGEH1 are yet to be explored concerning prognosis. Besides, due to some conflicting findings from different databases, we still can't make a blanket statement about MAGEH1.

\section{Materials And Methods}


The discrepancy of MAGEH1 expression in various tumor tissues versus corresponding normal tissues was examined in the Oncomine database (https://www.Oncomi ne.org/resource/login.html) [41]. And statistical analysis of the difference was used by the student's T-test. The threshold was set at: P-value: 0.001 , fold change: 1.5, gene rank: ALL. Then the differential expression of MAGEH1 gene was ascertained in the TCGA database via the Gene_DE part in TIMER2.0 (http://timer.comp-genomics.org/) [42] and the results were shown with boxplots.

Prognostic assessment in PrognoScan, Kaplan-Meier Plotter, GEPIA, and Human Protein Atlas database

PrognoScan (http://dna00.bio.kyutech.ac.jp/PrognoScan/index.html; results selected by Cox P-value<0.05), Kaplan-Meier Plotter (https://kmplot.com/analysis/), GEPIA (http://gepia.cancer-pku.cn/) and HPA (http://ww w.proteinatlas.org; the criterion was set at P<0.05)[43-46] was employed to evaluate the prognostic value of MAGEH1. Specifically, the MAGEH1 mRNA level was searched in PrognoScan to identify its relevance of prognosis, such as OS. The survival analysis of the PrognoScan was visualized by GraphPad Prism 8.4.3 Software [47]and EXCEL. Kaplan-Meier Plotter, a powerful online tool was performed to analyze the relevance of MAGEH1 expression with Survival index. We applied GEPIA, an interactive web server for analyzing the tumors/normal clinical specimens' data from the Genotype Tissue Expression projects and TCGA, to examine the influence of MAGEH1 on OS and DFS in 34 tumor types, and further validated the prognostic significance in TCGA data by the Human Protein Atlas database.

\section{Subgroup analysis of GC in Kaplan-Meier Plotter}

Patients were divided by "median", and the follow-up threshold was set as ALL in the Kaplan-Meier Plotter database. Survival analysis of subgroup analysis was performed separately in distinct subtypes and queues and all other default settings. We carried out GraphPad Prism 8.4.3 Software and EXCEL to draw the subgroup analysis data obtained by Kaplan-Meier Plotter into a visual forest plot.

\section{Estimation of immune infiltration}

We applied Gene and Survival Module in TIMER2.0 (http://timer.comp-genom ics.org/) to calculate the relationships between MAGEH1 expression and 6 types of tumor-infiltrating cells (B cells, CD4 + T cells, CD8 + T cells, macrophages, neutrophils, and dendritic cells), in STAD, LGG and ACC. The connection with genetic markers of tumor-infiltrating cells conditioned on tumor purity was computed in Gene_Corr module. We further verified associations in GEPIA (http://gepia.cancer-pku.cn/index.html); under other default settings, spearman's correlation analysis was selected to analyze the tumor and normal tissue datasets.

\section{Statistical analysis}

The statistically significant difference of various expression levels of MAGEH1 in tumor versus normal groups was calculated by T-test. Kaplan-Meier curves were utilized to compare the prognostic differences, which displayed as $\mathrm{P}$ or Cox P-values determined by the log-rank test and $\mathrm{HR}$ with $95 \% \mathrm{Cl}$. Relation of gene expression was tested with Spearman's correlation. The level of significance was defined by a P-value $<0.05$, if not especially noted.

\section{Abbreviations}

GC: Gastric cancer; LISC: hepatocellular carcinoma; Tregs: regulatory T cells; NSCLC: non-small cell lung changer; CRC: colorectal cancer; TME: the tumor microenvironment; TCGA: the Cancer Genome Atlas; BLCA: Bladder Urothelial Carcinoma; BRCA: Breast invasive carcinoma; CESC: Cervical squamous cell carcinoma and endocervical adenocarcinoma; COAD: Colon adenocarcinoma; GBM: Glioblastoma multiforme; KICH: Kidney Chromophobe; KIRC: Kidney renal clear cell carcinoma; KIRP: Kidney renal papillary cell carcinoma; LUAD: Lung adenocarcinoma; LUSC: Lung squamous cell carcinoma; PRAD: Prostate adenocarcinoma; READ: Rectum adenocarcinoma; STAD: Stomach adenocarcinoma; THCA: Thyroid carcinoma; UCEC: Uterine Corpus Endometrial Carcinoma; CHOL: Cholangiocarcinoma; HNSC: Head and Neck squamous cell carcinoma; HR: Hazard ratio; Cl: confidence intervals; OS: overall survival; PPS: post-progression survival; GEPIA: Gene Expression Profiling Interactive Analysis; HPA: Human Protein Atlas database; DFS: disease-free survival; LGG: Brain Lower Grade Glioma; OV: ovarian serous cystadenocarcinoma; PAAD: Pancreatic adenocarcinoma; SKCM: Skin Cutaneous Melanoma; 5-FU: 5- fluorouracil; DCs: dendritic cells; ACC: Adrenocortical carcinoma; TAMs: tumor-related macrophages.

\section{Declarations}

\section{Acknowledgments:}

Thanks for the support from the Department of Gastroenterology, Nanfang Hospital, Southern Medical University.

\section{Ethics approval and consent to participate:}

Since the data was obtained from a public database, approval from the Ethics committee or written informed consent from patients was not required.

\section{Consent for publication:}


Not applicable.

Availability of data and materials:

Publicly available datasets were analyzed in this study. This data can be found at: https://ww w.Oncomine.org/resource/login.html; http://timer.compgenomics.org/; http://dna00.bio.kyutech.ac.jp/PrognoScan/index.html; https://kmp lot.com/analysis/; http://gepia.cancer-pku.cn/; http://ww w.proteinatlas.org. The supplementary material for this article can be found online. All processed data in this study can be obtained from the corresponding author on reasonable request.

Conflicts of Interest:

The authors declare no conflict of interest.

Funding:

This research was funded by National Major New Drug Creation Science and Technology Major Special Fund Funding Project, grant number 2020ZX09201017, and Special Scientific Research Fund for National Natural Science Foundation of China, grant number 8177031240.

Author Contributions:

Conceptualization, Y.C. and Z.L.; methodology, H.K. and W.D.; validation, W.D. and S.W.; data curation, Z.L. and F.L.; writing-original draft preparation, H.K. and W.D.; writing-review and editing, Z.L. and H.K.; supervision, Y.C.; funding acquisition, Y.C. All authors have read and agreed to the published version of the manuscript.

\section{References}

1. F B, J F, I S, RL S, LA T, A J: Global cancer statistics 2018: GLOBOCAN estimates of incidence and mortality worldwide for 36 cancers in 185 countries. CA: a cancer journal for clinicians 2018, 68(6):394-424.

2. Park S, Nam CM, Kim S, Mun JE, Rha SY, Chung HC: Comparative efficacy and tolerability of third-line treatments for advanced gastric cancer: A systematic review with Bayesian network meta-analysis. EUR J CANCER 2021, 144:49-60.

3. K M, Van Cutsem E, Y N, G P, E B, J L, MH R, WIW Z, WP Y, KH Y et al: Pan-Asian adapted ESMO Clinical Practice Guidelines for the management of patients with metastatic gastric cancer: a JSMO-ESMO initiative endorsed by CSCO, KSMO, MOS, SSO and TOS. Annals of oncology: official journal of the European Society for Medical Oncology 2019, 30(1):19-33.

4. E F, EC S: Novel targets in the treatment of advanced gastric cancer: a perspective review. THER ADV MED ONCOL 2016, 8(2):113-125.

5. Wang F, Shen L, Li J, Zhou Z, Liang H, Zhang X, Tang L, Xin Y, Jin J, Zhang Y et al: The Chinese Society of Clinical Oncology (CSCO): clinical guidelines for the diagnosis and treatment of gastric cancer. Cancer Communications 2019, 39(1):10.

6. Dolcetti R, De Re V, Canzonieri V: Immunotherapy for Gastric Cancer: Time for a Personalized Approach? INT J MOL SCI $2018,19(6): 1602$.

7. Abdul-Latif M, Townsend K, Dearman C, Shiu KK, Khan K: Immunotherapy in gastrointestinal cancer: The current scenario and future perspectives. CANCER TREAT REV 2020, 88:102030.

8. Le DT, Durham JN, Smith KN, Wang H, Bartlett BR, Aulakh LK, Lu S, Kemberling H, Wilt C, Luber BS et al: Mismatch repair deficiency predicts response of solid tumors to PD-1 blockade. SCIENCE 2017, 357(6349):409-413.

9. Chen $\mathrm{KH}$, Yuan $\mathrm{CT}$, Tseng LH, Shun $\mathrm{CT}$, Yeh $\mathrm{KH}$ : Case report: mismatch repair proficiency and microsatellite stability in gastric cancer may not predict programmed death-1 blockade resistance. J HEMATOL ONCOL 2016, 9:29.

10. Wang F, Wei XL, Wang FH, Xu N, Shen L, Dai GH, Yuan XL, Chen Y, Yang SJ, Shi JH et al: Safety, efficacy and tumor mutational burden as a biomarker of overall survival benefit in chemo-refractory gastric cancer treated with toripalimab, a PD-1 antibody in phase lb/II clinical trial NCT02915432. ANN ONCOL 2019, 30(9):1479-1486.

11. Lin C, He H, Liu H, Li R, Chen Y, Qi Y, Jiang Q, Chen L, Zhang P, Zhang H et al: Tumour-associated macrophages-derived CXCL8 determines immune evasion through autonomous PD-L1 expression in gastric cancer. GUT 2019, 68(10):1764-1773.

12. H Z, H L, Z S, C L, X W, J Q, X Q, J X, Y S: Tumor-infiltrating Neutrophils is Prognostic and Predictive for Postoperative Adjuvant Chemotherapy Benefit in Patients with Gastric Cancer. ANN SURG 2018, 267(2):311-318.

13. Ross MT, Grafham DV, Coffey AJ, Scherer S, McLay K, Muzny D, Platzer M, Howell GR, Burrows C, Bird CP et al: The DNA sequence of the human X chromosome. NATURE 2005, 434(7031):325-337.

14. PA B, A S: The MAGE proteins: emerging roles in cell cycle progression, apoptosis, and neurogenetic disease. J NEUROSCI RES 2002, 67(6):705712.

15. Fu H, Yang G, Lu F, Wang R, Yao L, Lu Z: Transcriptional up-regulation of restin by all-trans retinoic acid through STAT1 in cancer cell differentiation process. Biochem Biophys Res Commun 2006, 343(4):1009-1016.

16. Tcherpakov M, Bronfman FC, Conticello SG, Vaskovsky A, Levy Z, Niinobe M, Yoshikawa K, Arenas E, Fainzilber M: The p75 neurotrophin receptor interacts with multiple MAGE proteins. J BIOL CHEM 2002, 277(51):49101-49104. 
17. Ojima H, Yoshikawa D, Ino Y, Shimizu H, Miyamoto M, Kokubu A, Hiraoka N, Morofuji N, Kondo T, Onaya H et al: Establishment of six new human biliary tract carcinoma cell lines and identification of MAGEH1 as a candidate biomarker for predicting the efficacy of gemcitabine treatment. CANCER SCI 2010, 101(4):882-888.

18. Wang PC, Hu ZQ, Zhou SL, Zhan H, Zhou ZJ, Luo CB, Huang XW: Downregulation of MAGE family member H1 enhances hepatocellular carcinoma progression and serves as a biomarker for patient prognosis. FUTURE ONCOL 2018, 14(12):1177-1186.

19. Jia B, Zhao X, Wang Y, Wang J, Wang Y, Yang Y: Prognostic roles of MAGE family members in breast cancer based on KM-Plotter Data. ONCOL LETT 2019, 18(4):3501-3516.

20. Plitas G, Konopacki C, Wu K, Bos PD, Morrow M, Putintseva EV, Chudakov DM, Rudensky AY: Regulatory T Cells Exhibit Distinct Features in Human Breast Cancer. IMMUNITY 2016, 45(5):1122-1134.

21. De Simone M, Arrigoni A, Rossetti G, Gruarin P, Ranzani V, Politano C, Bonnal R, Provasi E, Sarnicola ML, Panzeri I et al: Transcriptional Landscape of Human Tissue Lymphocytes Unveils Uniqueness of Tumor-Infiltrating T Regulatory Cells. IMMUNITY 2016, 45(5):1135-1147.

22. JL W, PR P: The MAGE protein family and cancer. CURR OPIN CELL BIOL 2015, 37:1-8.

23. Rhodes DR, Kalyana-Sundaram S, Mahavisno V, Varambally R, Yu J, Briggs BB, Barrette TR, Anstet MJ, Kincead-Beal C, Kulkarni P et al: Oncomine 3.0: genes, pathways, and networks in a collection of 18,000 cancer gene expression profiles. NEOPLASIA 2007, 9(2):166-180.

24. Li T, Fu J, Zeng Z, Cohen D, Li J, Chen Q, Li B, Liu XS: TIMER2.0 for analysis of tumor-infiltrating immune cells. NUCLEIC ACIDS RES 2020, 48(W1): W509-W514.

25. Mizuno H, Kitada K, Nakai K, Sarai A: PrognoScan: a new database for meta-analysis of the prognostic value of genes. BMC MED GENOMICS 2009, 2:18.

26. Tang Z, Li C, Kang B, Gao G, Li C, Zhang Z: GEPIA: a web server for cancer and normal gene expression profiling and interactive analyses. NUCLEIC ACIDS RES 2017, 45(W1): W98-W102.

27. Lánczky A, Nagy Á, Bottai G, Munkácsy G, Szabó A, Santarpia L, Győrffy B: miRpower: a web-tool to validate survival-associated miRNAs utilizing expression data from 2178 breast cancer patients. Breast Cancer Res Treat 2016, 160(3):439-446.

28. Uhlén M, Fagerberg L, Hallström BM, Lindskog C, Oksvold P, Mardinoglu A, Sivertsson Å, Kampf C, Sjöstedt E, Asplund A et al: Proteomics. Tissuebased map of the human proteome. SCIENCE 2015, 347(6220):1260419.

29. Singh AK, Singh R: SAVOR-TIMI to DECLARE-TIMI: A Review on Cardiovascular Outcome Trials of Incretin-modulators and Gliflozins. Indian J Endocrinol Metab 2019, 23(2):175-183.

30. Bindea G, Mlecnik B, Tosolini M, Kirilovsky A, Waldner M, Obenauf AC, Angell H, Fredriksen T, Lafontaine L, Berger A et al: Spatiotemporal dynamics of intratumoral immune cells reveal the immune landscape in human cancer. IMMUNITY 2013, 39(4):782-795.

31. Kang BW, Seo AN, Yoon S, Bae HI, Jeon SW, Kwon OK, Chung HY, Yu W, Kang H, Kim JG: Prognostic value of tumor-infiltrating lymphocytes in Epstein-Barr virus-associated gastric cancer. ANN ONCOL 2016, 27(3):494-501.

32. Zheng J, Li Q, Wang W, Wang Y, Fu X, Wang W, Fan L, Yan W: Apoptosis-related protein-1 acts as a tumor suppressor in cholangiocarcinoma cells by inducing cell cycle arrest via downregulation of cyclin-dependent kinase subunits. ONCOL REP 2016, 35(2):809-816.

33. Skvortsova K, Stirzaker C, Taberlay P: The DNA methylation landscape in cancer. ESSAYS BIOCHEM 2019, 63(6):797-811.

34. Longley DB, Harkin DP, Johnston PG: 5-fluorouracil: mechanisms of action and clinical strategies. NAT REV CANCER 2003, 3(5):330-338.

35. Qiao L, Wong BC: Targeting apoptosis as an approach for gastrointestinal cancer therapy. Drug Resist Updat 2009, 12(3):55-64.

36. Selimovic D, Sprenger A, Hannig M, Haïkel Y, Hassan M: Apoptosis related protein-1 triggers melanoma cell death via interaction with the juxtamembrane region of p75 neurotrophin receptor. J CELL MOL MED 2012, 16(2):349-361.

37. Bindea G, Mlecnik B, Tosolini M, Kirilovsky A, Waldner M, Obenauf AC, Angell H, Fredriksen T, Lafontaine L, Berger A et al: Spatiotemporal dynamics of intratumoral immune cells reveal the immune landscape in human cancer. IMMUNITY 2013, 39(4):782-795.

38. Aran D, Sirota M, Butte AJ: Systematic pan-cancer analysis of tumour purity. NAT COMMUN2015, 6:8971.

39. Wang TT, Zhao YL, Peng LS, Chen N, Chen W, Lv YP, Mao FY, Zhang JY, Cheng P, Teng YS et al: Tumour-activated neutrophils in gastric cancer foster immune suppression and disease progression through GM-CSF-PD-L1 pathway. GUT 2017, 66(11):1900-1911.

40. Gambardella V, Castillo J, Tarazona N, Gimeno-Valiente F, Martínez-Ciarpaglini C, Cabeza-Segura M, Roselló S, Roda D, Huerta M, Cervantes A et al: The role of tumor-associated macrophages in gastric cancer development and their potential as a therapeutic target. CANCER TREAT REV 2020, 86:102015.

41. Togashi Y, Shitara K, Nishikawa H: Regulatory T cells in cancer immunosuppression - implications for anticancer therapy. NAT REV CLIN ONCOL 2019, 16(6):356-371.

42. Hori S, Nomura T, Sakaguchi S: Control of regulatory T cell development by the transcription factor Foxp3. SCIENCE 2003, 299(5609):1057-1061.

43. Achyut BR, Yang L: Transforming growth factor-beta in the gastrointestinal and hepatic tumor microenvironment. GASTROENTEROLOGY 2011, 141(4):1167-1178.

44. Plitas G, Konopacki C, Wu K, Bos PD, Morrow M, Putintseva EV, Chudakov DM, Rudensky AY: Regulatory T Cells Exhibit Distinct Features in Human Breast Cancer. IMMUNITY 2016, 45(5):1122-1134.

Page 11/15 
45. Liao L, Song M, Li X, Tang L, Zhang T, Zhang L, Pan Y, Chouchane L, Ma X: E3 Ubiquitin Ligase UBR5 Drives the Growth and Metastasis of TripleNegative Breast Cancer. CANCER RES 2017, 77(8):2090-2101.

46. Erdem-Eraslan L, Heijsman D, de Wit M, Kremer A, Sacchetti A, van der Spek PJ, Sillevis SP, French PJ: Tumor-specific mutations in low-frequency genes affect their functional properties. $J$ Neurooncol 2015, 122(3):461-470.

47. Eisenhaber F, Bork P: Wanted: subcellular localization of proteins based on sequence. TRENDS CELL BIOL 1998, 8(4):169-170.

\section{Figures}

\section{a. MAGEH1}

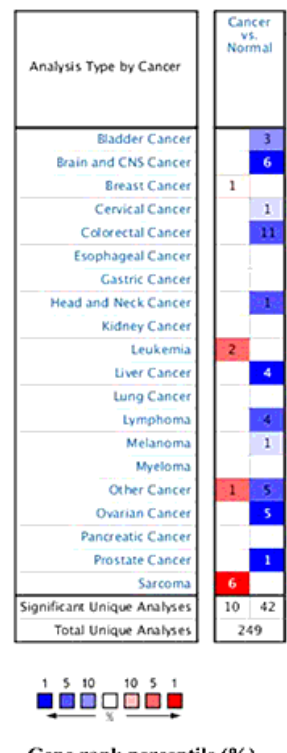

b.

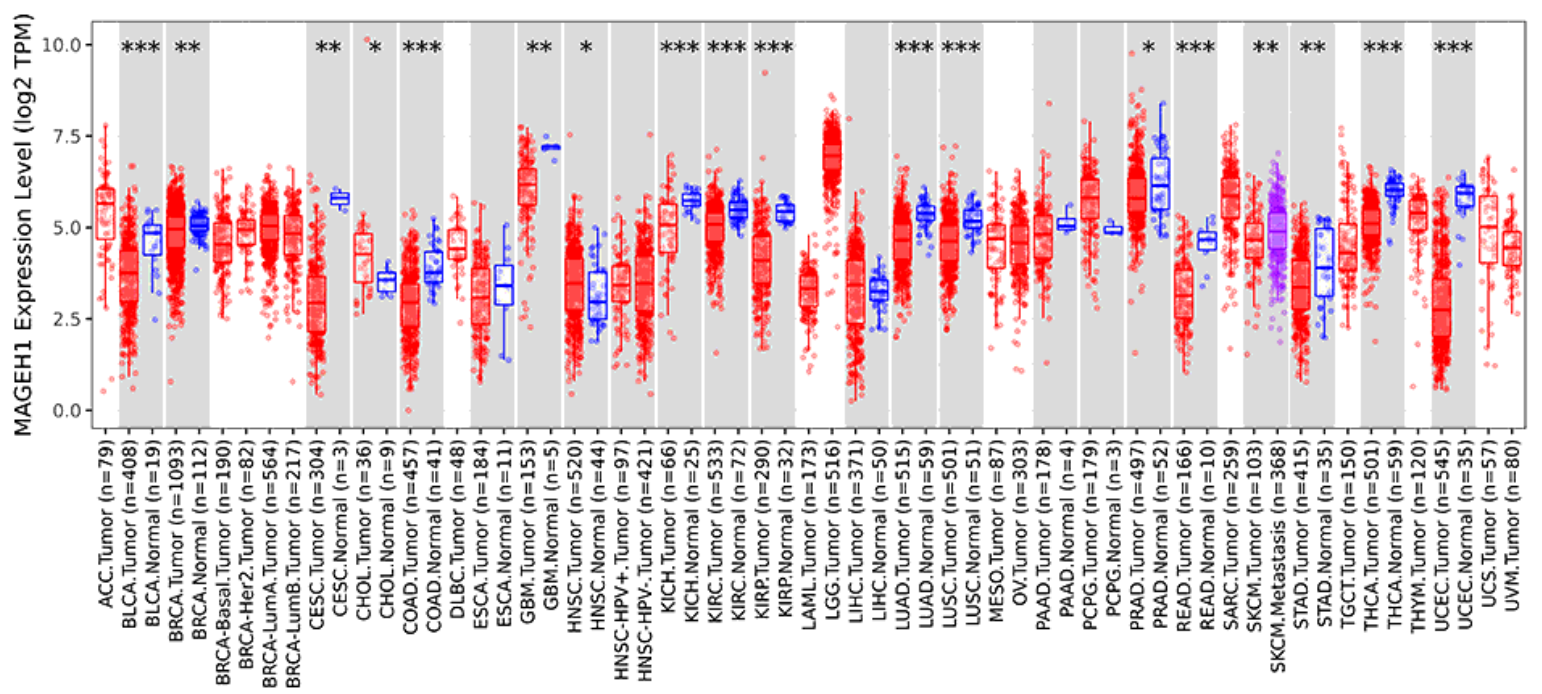

Figure 1

MAGEH1 expression levels in various cancer tissues. (a) The discrepancy of MAGEH1 expression between diverse cancers and normal adjacent tissues in the Oncomine database. Number in cells represent the number of data sets. (b) MAGEH1 expression in 38 cancer tissues from TCGA database in TIMER2.0 (*P $<0.05, * * \mathrm{P}<0.01, * \star * \mathrm{P}<0.001)$. 

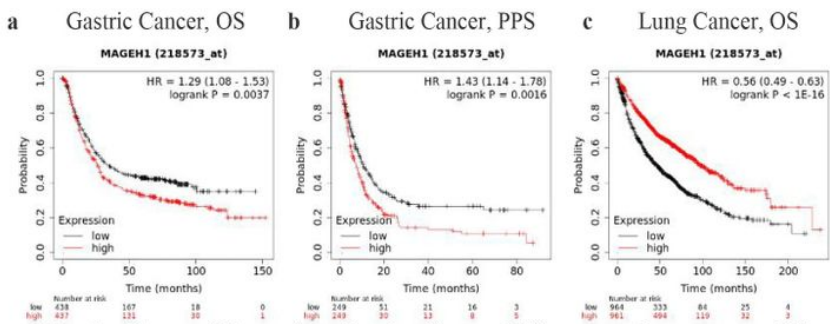

d Lung Cancer, PPS

e Ovarian Cancer, OS f Ovarian Cancer, PFS
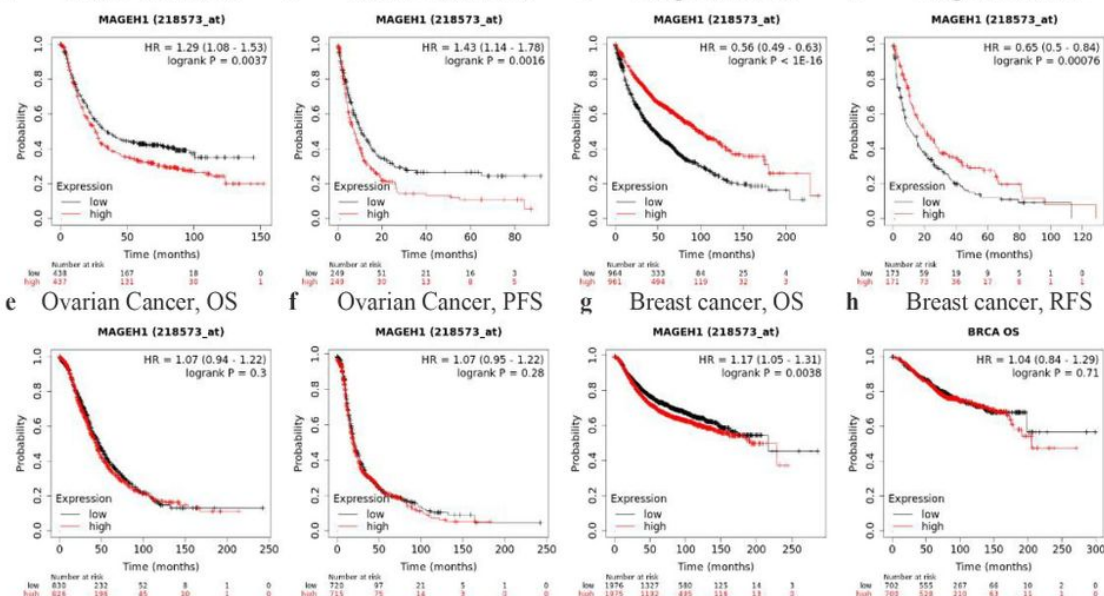

h Breast cancer, RFS
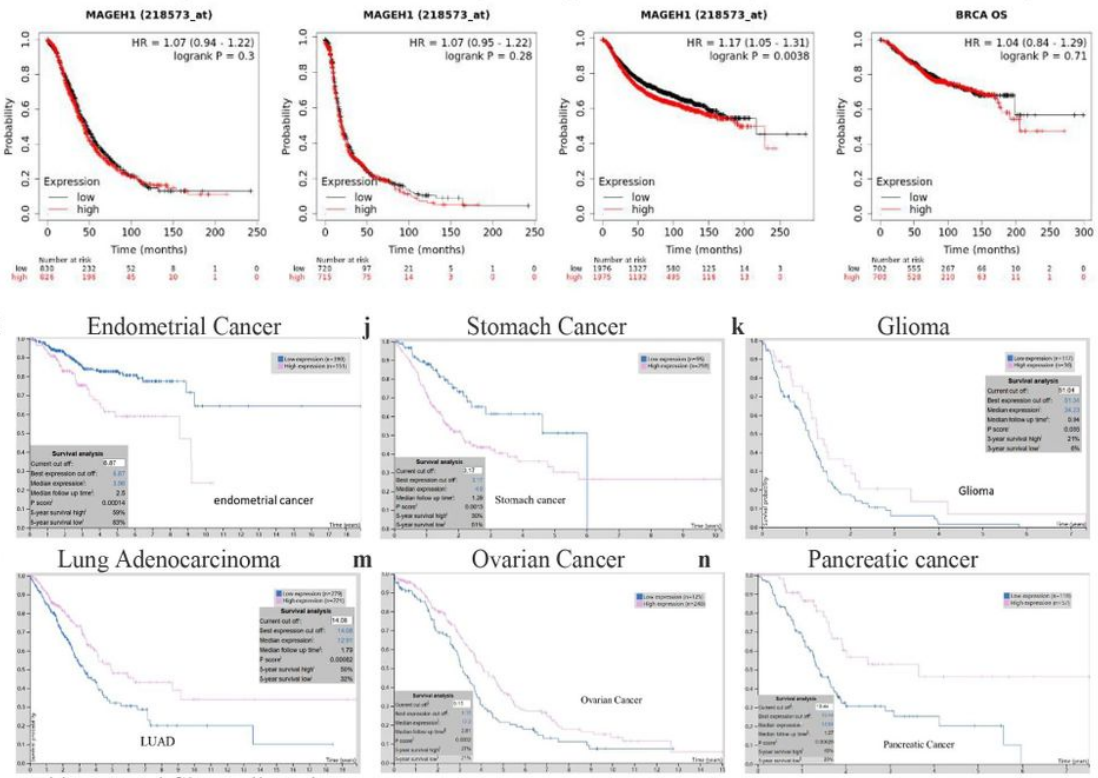

Pancreatic cancer

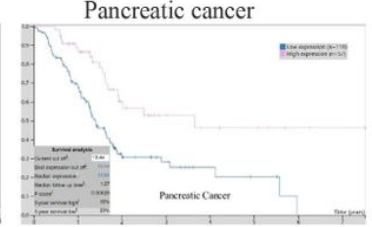

o Kidney Renal Clear cell carcinoma

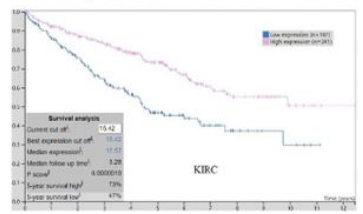

Figure 2

Comparison on Kaplan-Meier survival curves of increased and decreased MAGEH1 in various types of tumor in Kaplan-Meier plotter databases (a-h) and Human Protein Atlas databases (i-n). (a, b) OS and PPS curves for gastric cancer patients ( $n=875, n=498)$. (c, d) OS and PPS curves for lung cancer patients $(n=1,925, n=344)$. (e, f) OS and PFS curves for ovarian cancer patients $(n=1,656, n=1,435)$. ( $g$, h) OS and RFS curves for breast cancer patients ( $n=1,402, n=3,951)$. Five-year survival rate of (i) Endometrial Cancer ( $n=541)$; (j) Stomach Cancer ( $n=354)$; (k) Glioma ( $n=153)$; (l) Lung Adenocarcinoma ( $n=500)$; (m) Ovarian Cancer ( $n=373)$; $(n)$ Pancreatic cancer $(n=176)$; (o) Kidney Renal Clear cell carcinoma ( $n=528)$. 0S, overall survival; PPS, post progression survival; PFS, progression free survival; RFS, relapse-free survival. 


\begin{tabular}{|c|c|c|c|c|c|c|c|c|}
\hline \multirow{2}{*}{$\begin{array}{c}\text { Clinicopathological } \\
\text { characteristics }\end{array}$} & \multicolumn{4}{|c|}{ Overall survival $(n=875)$} & \multicolumn{4}{|c|}{ Progression-free survival $(n=640)$} \\
\hline & total/N & & Hazard ratio & P-value & total/N & & Hazard ratio & P-value \\
\hline \multicolumn{9}{|l|}{ Sex } \\
\hline Female & 236 & -1 & $1.26(0.89-1.79)$ & 0.190 & 201 & -1 & $1.23(0.84-1.8)$ & 0.28 \\
\hline Male & 544 & -1 & $1.3(1.05-1.61)$ & 0.016 & 437 & 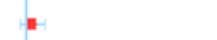 & $1.12(0.88-1.42)$ & 0.35 \\
\hline \multicolumn{9}{|l|}{ Stage } \\
\hline 1 & 67 & 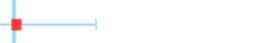 & $1.06(0.39-2.91)$ & 0.910 & 60 &. & $0.84(0.27-2.59)$ & 0.76 \\
\hline 2 & 140 & $\square$ & $1.66(0.9-3.08)$ & 0.102 & 131 & $\mapsto$ & $1.11(0.6-2.05)$ & 0.73 \\
\hline 3 & 305 & 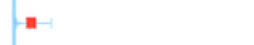 & $1.4(1.05-1.87)$ & 0.021 & 186 & -1 & $1.44(0.99-2.09)$ & 0.054 \\
\hline 4 & 148 & $\because$ & $1.49(1.01-2.2)$ & 0.043 & 141 & $=1$ & $1.09(0.74-1.6)$ & 0.67 \\
\hline \multicolumn{9}{|l|}{ Stage $T$} \\
\hline 2 & 241 & 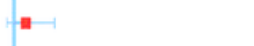 & $1.27(0.83-1.95)$ & 0.260 & 239 & -1 & $1.12(0.74-1.69)$ & 0.6 \\
\hline 3 & 204 & -1 & $1.21(0.86-1.71)$ & 0.280 & 204 & - & $1.17(0.84-1.63)$ & 0.37 \\
\hline 4 & 38 & $=-\rightarrow$ & $2.57(1.02-6.49)$ & 0.040 & 39 & -1 & $1.94(0.87-4.31)$ & 0.098 \\
\hline \multicolumn{9}{|l|}{ Stage $\mathbf{N}$} \\
\hline 0 & 74 & 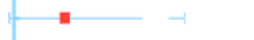 & $2.19(0.89-5.41)$ & 0.082 & 72 & $\because-\dashv$ & $2.14(0.87-5.27)$ & 0.092 \\
\hline 1 & 225 & $\mapsto$ & $2.1(1.37-3.2)$ & $4.40 \mathrm{E}-04$ & 222 & $\because$ & $1.64(1.11-2.44)$ & 0.013 \\
\hline 2 & 121 & -1 & $1.21(0.78-1.90)$ & 0.400 & 125 & $=1$ & $1.17(0.76-1.79)$ & 0.49 \\
\hline 3 & 76 & $\square$ & $1.58(0.93-2.70)$ & 0.089 & 76 & 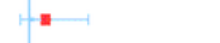 & $1.36(0.8-2.3)$ & 0.25 \\
\hline $1+2+3$ & 442 & $1-$ & $1.64(1.26-2.14)$ & $2.30 \mathrm{E}-04$ & 423 & - & $1.48(1.15-1.9)$ & 0.0025 \\
\hline \multicolumn{9}{|l|}{ Stage M } \\
\hline 0 & 444 & -1 & $1.6(1.21-2.12)$ & $9.60 \mathrm{E}-04$ & 443 & -1 & $1.38(1.06-1.81)$ & 0.017 \\
\hline 1 & 56 & - & $1.11(0.62-1.98)$ & 0.720 & 56 & $\mapsto$ & $0.98(0.55-1.77)$ & 0.96 \\
\hline \multicolumn{9}{|l|}{ Lauern clasification } \\
\hline Intestinal & 320 & - & $1.68(1.22-2.32)$ & $1.20 \mathrm{E}-03$ & 263 & - & $1.67(1.17-2.39)$ & 0.0041 \\
\hline Diffuse & 241 & $\mapsto$ & $1.86(1.31-2.63)$ & $3.80 \mathrm{E}-04$ & 231 & $=1$ & $1.63(1.15-2.31)$ & 0.0051 \\
\hline Mixed & 32 & 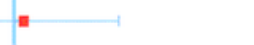 & $1.22(0.43-3.44)$ & 0.710 & 28 & 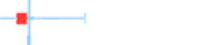 & $0.84(0.31-2.24)$ & 0.72 \\
\hline \multicolumn{9}{|l|}{ Differentiation } \\
\hline Poor & 165 & 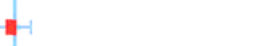 & $0.92(0.62-1.37)$ & 0.680 & 121 & +1 & $0.84(0.53-1.33)$ & 0.46 \\
\hline Moderate & 67 & 7 & $1.34(0.7-2.58)$ & 0.380 & 67 & $\mapsto$ & $1.33(0.71-2.49)$ & 0.37 \\
\hline Well differentiated & 32 & -1 & $1.56(0.66-3.71)$ & 0.310 & 5 & & - & - \\
\hline \multicolumn{9}{|l|}{ Treatment } \\
\hline Surgery only & 380 & - & $1.37(1.03-1.83)$ & 0.031 & 375 & -1 & $1.31(0.99-1.73)$ & 0.059 \\
\hline 5-FU based adjuvant & 152 & & $0.62(0.43-0.88)$ & $6.80 \mathrm{E}-03$ & 152 & - & $0.62(0.44-0.89)$ & 0.0082 \\
\hline Other adjuvant & 76 & 1) & $2.19(0.87-5.49)$ & 0.087 & 80 & ॥ & $2.48(1.07-5.76)$ & 0.028 \\
\hline
\end{tabular}

Figure 3

Correlation of MAGEH1 mRNA expression in gastric cancer with different clinicopathological features by Kaplan-Meier plotter. Red squares denote hazard ratio. Short bar represents that hazard ratio cannot be calculated due to too small sample size. Bold values indicate $\mathrm{P}<0.05$. 
$\mathbf{a}$

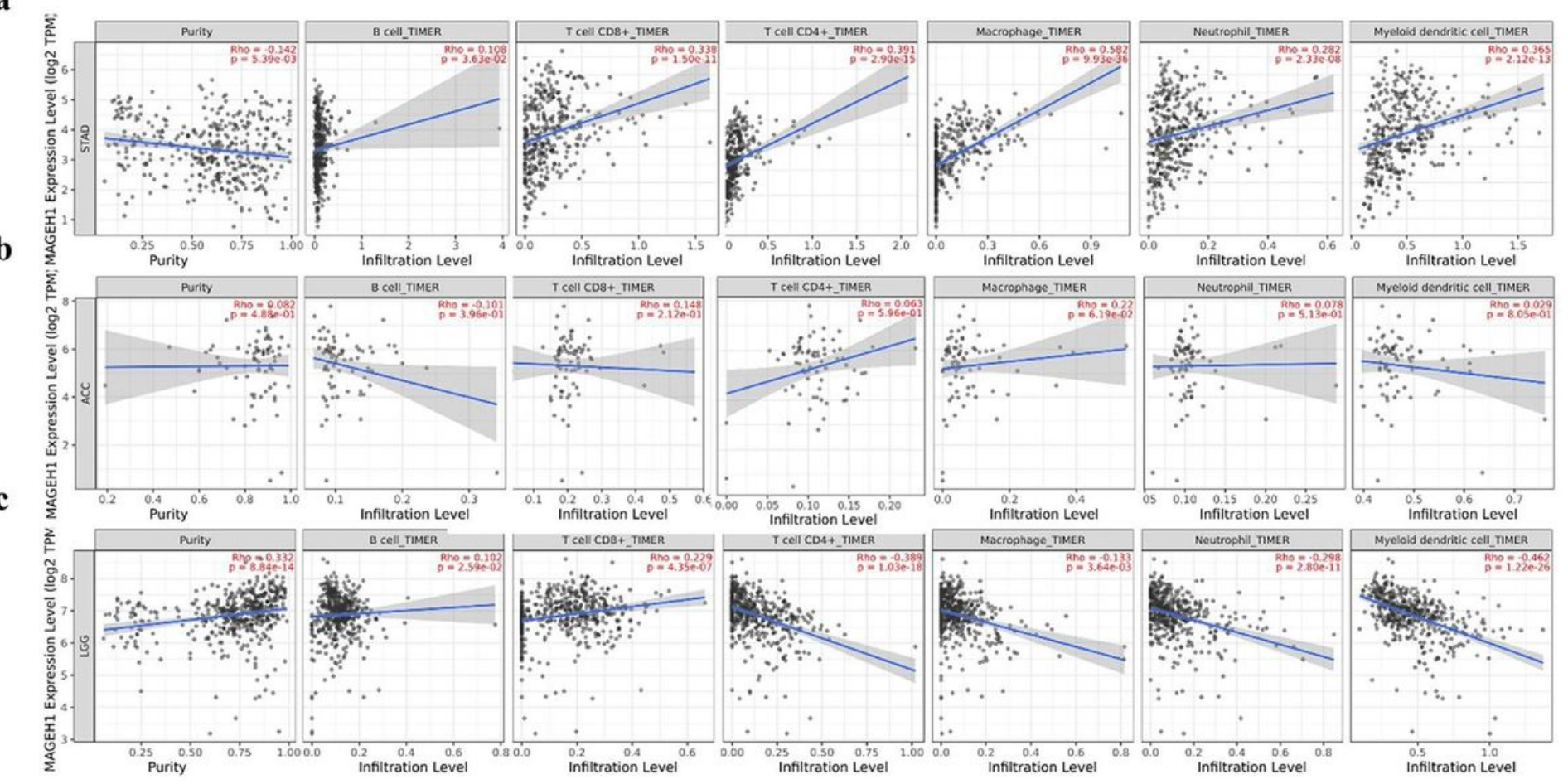

\section{Figure 4}

Immune infiltration level correlating to MAGEH1 expression in STAD, ACC, and LGG. (a) A significant association with MAGEH1 expression is discovered in tumor purity (negative correlation) and. infiltrating levels of CD8+ T cells, CD4+ T cells, macrophages, neutrophils, and dendritic cells (positive correlation) in STAD ( $n=415)$. (b) MAGEH1 expression is not statistically correlated with tumor purity and infiltrating levels of B cells and the above 5 cells in ACC $(n=79)$. (c) MAGEH1 expression is remarkably positive associated with tumor purity and infiltrating levels of B cells and CD8+ T cells, and negative correlated to CD4+ T cells, macrophages, neutrophils, and dendritic cells in LGG $(n=516)$.

\section{Supplementary Files}

This is a list of supplementary files associated with this preprint. Click to download.

- Additionalfile1.docx

- Additionalfile2.docx

- additionalfile3.docx

- Additionalfile4.tif 